\title{
Prevalence of Peg-Shaped Lateral Incisors in Non-Syndromic Subjects: A Multi-Population Study
}

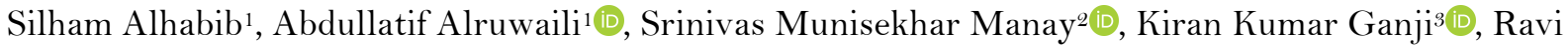

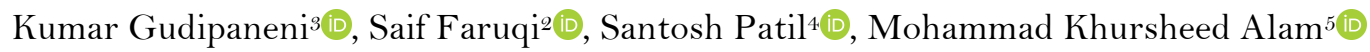

${ }^{1}$ College of Dentistry, Jouf University, Aljouf, Kingdom of Saudi Arabia.

${ }^{2}$ Department of Preventive Dentistry, College of Dentistry, Jouf University, Aljouf, Kingdom of Saudi Arabia.

sPeriodontics Section, Department of Preventive Dentistry, College of Dentistry, Jouf University, Aljouf, Kingdom of Saudi Arabia.

${ }^{4}$ New Horizon Dental College and Research Institute, Chhattisgarh, India.

${ }^{5}$ Orthodontics Section, Department of Preventive Dentistry, College of Dentistry, Jouf University, Aljouf, Kingdom of Saudi Arabia.

Author to whom correspondence should be addressed: Dr. Mohammad Khursheed Alam, Associate Professor, Orthodontics Section, Department of Preventive Dentistry, College of Dentistry, Jouf University, Aljouf, Kingdom of Saudi Arabia. Phone: +966535602339. E-mail: dralam@gmail.com

Academic Editor: Alidianne Fábia Cabral Cavalcanti

Received: 02 April 2020 / Review: 10 June 2020 / Accepted: 24 June 2020

How to cite this article: Alhabib S, Alruwaili A, Manay SM, Ganji KK, Gudipaneni RK, Faruqi S, et al. Prevalence of pegshaped lateral incisors in non-syndromic subjects: a multi-population study. Pesqui Bras Odontopediatria Clín Integr. 2020; 20:e0066. https://doi.org/10.1590/pboci.2020.165

\begin{abstract}
Objective: To evaluate the prevalence and gender-wise distribution of peg-shaped maxillary permanent lateral incisors among populations in Saudi Arabia representing different geographical locations (Saudi, Jordan, Egypt, Syria, Philippine, Pakistan, India and Bangladesh). Material and Methods: Panoramic radiographs of 9945 patients attending outpatient university dental clinics of College of Dentistry, Jouf University, Saudi Arabia between February 2014 and January 2018 were collected from the archives randomly. Two calibrated investigators examined the data, which were collected from the dental radiology department archives with prior permission from the authorities. The anomalies of maxillary lateral incisors (right and left) were investigated. Results: Among all geographic locations, the prevalence of peg laterals was more in males in comparison to females except in Pakistani and Philippine populations. Among the Saudi population, peg laterals' prevalence was more in case of right lateral incisor than the left incisor. Conclusion: A higher prevalence of peg laterals was found in Saudi. Conclusion: A higher prevalence of peg laterals was found in Saudi region, followed by Egypt. Among all geographic locations, the prevalence of peg laterals was higher in males than females except for Pakistan and Philippines populations. Among Saudi population prevalence of peg laterals was found to be higher in case of right lateral incisor when compared to the left.
\end{abstract}

Keywords: Tooth Abnormalities; Epidemiology; Radiography, Dental; Radiography, Panoramic. 


\section{Introduction}

A peg-shaped tooth, by definition, is a tooth with incisal and mesiodistal width of the crown shorter than the cervical width [1]. In general, all teeth belonging to the deciduous and permanent dentitions have fairly consistent and definite morphological features with a little variation. However, the permanent third molar has been considered the tooth that shows a great variation in its form, followed by the maxillary permanent lateral incisor [2].

Peg laterals' occurrence is multifactorial, with the main emphasis on the presence of an underlying genetic factor. The significance of such mechanism that determines the tooth size and morphological features have been shown by various studies [3-7]. The underlying genetic mechanism that results in agenesis of the maxillary permanent lateral incisors is also said to result in the formation of peg-shaped laterals [8,9]. Previous authors have strongly expressed that microdontia is a variable expression of the same developmental disturbance that results in tooth agenesis [10]. In addition to the genetic factor, studies also indicated the possible environmental factors for microdontia occurrence [11,12]. In a study carried out in Gizan province of Saudi Arabia, the prevalence of peg-shaped lateral incisors was reported to be $0.37 \%$ [13], in Pakistan it was reported to be $1.3 \%$ [14], 2.58\% in Indian population [15], and 2.3\% in Jordanian population [16]. The prevalence rates of peg laterals ranges between $0.6 \%$ to $9.9 \%[17,18]$. However, the prevalence rates have varied in different geographic locations, races and genders.

Hence, the present study was undertaken to evaluate the prevalence and gender-wise distribution of peg-shaped maxillary permanent lateral incisors among populations in different geographical locations.

\section{Material and Methods}

Study Design and Participants

This study was designed and conducted according to the Strengthening the Reporting of Observational Studies in Epidemiology (STROBE) guidelines [19].

The present study retrospectively examined panoramic radiographs with age groups ranging from 15 to 50 years. Data were randomly collected from the archives of Outpatient Department of University Dental Clinics, College of Dentistry, Jouf University, Saudi Arabia. The duration of the study period was from February 2014 to January 2018.

In order to be eligible to participate in this study, an individual must meet all of the following inclusion criteria: 1) Patients who have not undergone surgical removal or extraction of any tooth; 2) Only vivid radiographs were included. A patient was not eligible for the study if any one of the following exclusion criteria was present: 1) Patients with congenital disorders; 2) Patients with facial clefts or other craniofacial deformities; 3) Radiograph which shows pathologies like - tumors, cysts, etc.; and 4) Poor quality radiographs.

Based on inclusion and exclusion criteria, finally 9945 patients radiographs were found suitable to be recruited in the study.

\section{Data Collection}

All the radiographs were obtained by Cranex D (Soredex, Tuusula, Finland) and two calibre investigators examined the radiographs. Dental Radiology Department archives with prior permission from 
the authorities for research purposes only. All radiographs were re-evaluated by the same examiners after 14 days to check intra-observer variations and the reliability of measurements was evaluated by Kappa statistics. The reliability was very good, with Kappa values of 0.91 for observer 1 and 0.81 for observer 2 .

Data Analysis

Data were analyzed using IBM SPSS Statistics for Windows Software, version 20 (IBM Corp., Armonk, NY, USA). Descriptive statistics were used to calculate the absolute and relative frequencies.

Ethical Aspects

This study was approved by the Ethical Committee of the College of Dentistry (Protocol No. LCBE 916-8/39), which complies with the Declaration of Helsinki. Patient records/information were anonymized and de-identified prior to analysis and kept confidential.

\section{Results}

Out of 9945 panoramic radiographs evaluated, 6543 were males and 3402 females with the mean age \pm 32 years. All patients were examined for tooth morphology variation concerning peg lateral, normal and missing. Gender-wise comparison for the prevalence of peg laterals among different geographic locations is presented in Figure 1. Among all geographic locations, the prevalence of peg laterals was higher in males than females except for Pakistan and Philippines populations.

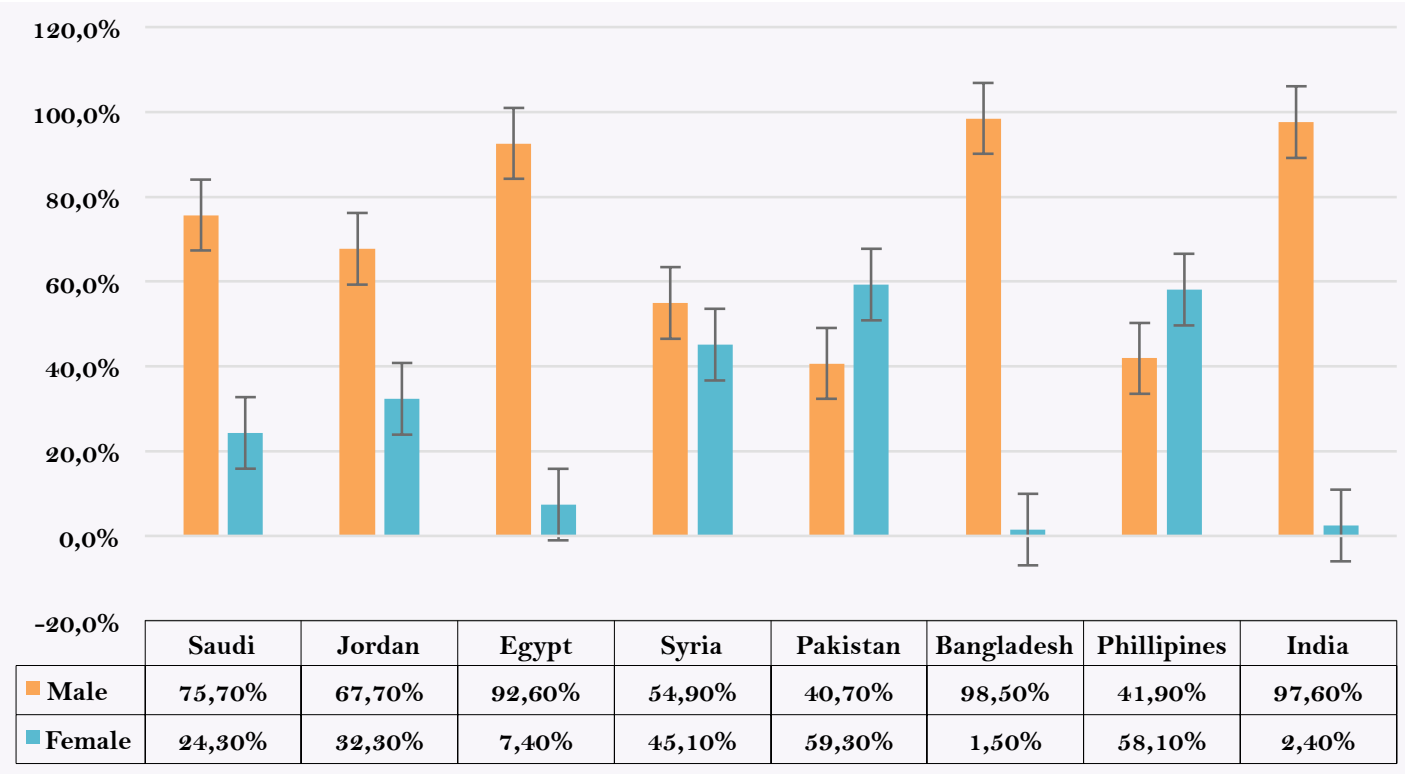

Figure 1. Gender wise distribution of peg-laterals among different geographic locations.

Prevalence of right peg laterals and left peg laterals in different geographic locations are presented in Table 1. Among Saudi population prevalence of peg laterals was found to be higher in case of right lateral incisor when compared to the left. 
Table 1. Comparison of peg-laterals among different geographic locations.

\begin{tabular}{|c|c|c|c|c|c|c|c|c|c|c|}
\hline \multirow{2}{*}{\multicolumn{2}{|c|}{ Tooth Morphology }} & \multicolumn{8}{|c|}{ Geographical Location } & \\
\hline & & \multirow[t]{2}{*}{ Saudi } & \multirow[t]{2}{*}{ Jordan } & \multirow[t]{2}{*}{ Egypt } & \multirow[t]{2}{*}{ Syria } & \multirow[t]{2}{*}{ Philippine } & \multirow[t]{2}{*}{ Pakistan } & \multirow[t]{2}{*}{ India } & \multirow[t]{2}{*}{ Bangladesh } & \\
\hline Right Lateral & & & & & & & & & & 10tai \\
\hline \multirow{3}{*}{ Peg } & $\mathrm{N}$ & 661 & $\mathrm{O}$ & $\mathrm{O}$ & $\mathrm{O}$ & 0 & 4 & 0 & 3 & 668 \\
\hline & \% within RL & $99.0 \%$ & $0.0 \%$ & $0.0 \%$ & $0.0 \%$ & $0.0 \%$ & $0.6 \%$ & $0.0 \%$ & $0.4 \%$ & $100.0 \%$ \\
\hline & \% within Race & $10.1 \%$ & $0.0 \%$ & $0.0 \%$ & $0.0 \%$ & $0.0 \%$ & $1.0 \%$ & $0.0 \%$ & $0.5 \%$ & $6.7 \%$ \\
\hline \multirow{3}{*}{ Normal } & $\mathrm{N}$ & 5752 & 818 & 664 & 566 & 86 & 416 & 327 & 543 & 9172 \\
\hline & \% within RL & $62.7 \%$ & $8.9 \%$ & $7.2 \%$ & $6.2 \%$ & $.9 \%$ & $4.5 \%$ & $3.6 \%$ & $5.9 \%$ & $100.0 \%$ \\
\hline & $\%$ within Race & $88.3 \%$ & $100.0 \%$ & $100.0 \%$ & $100.0 \%$ & $100.0 \%$ & $99.0 \%$ & $100.0 \%$ & $99.5 \%$ & $92.2 \%$ \\
\hline \multirow{3}{*}{ Missing } & $\mathrm{N}$ & 103 & 0 & 0 & 0 & 0 & 0 & 0 & 0 & 103 \\
\hline & \% within RL & $100.0 \%$ & $0.0 \%$ & $0.0 \%$ & $0.0 \%$ & $0.0 \%$ & $0.0 \%$ & $0.0 \%$ & $0.0 \%$ & $100.0 \%$ \\
\hline & \% within Race & $1.6 \%$ & $0.0 \%$ & $0.0 \%$ & $0.0 \%$ & $0.0 \%$ & $0.0 \%$ & $0.0 \%$ & $0.0 \%$ & $1.0 \%$ \\
\hline \multicolumn{11}{|l|}{ Left Lateral } \\
\hline \multirow{3}{*}{ Peg } & $\mathrm{N}$ & 106 & $\mathrm{O}$ & 10 & 3 & $\mathrm{O}$ & 3 & 0 & 0 & 122 \\
\hline & \% within LL & $86.9 \%$ & $0.0 \%$ & $8.2 \%$ & $2.5 \%$ & $0.0 \%$ & $2.5 \%$ & $0.0 \%$ & $0.0 \%$ & $100.0 \%$ \\
\hline & $\%$ within Race & $1.6 \%$ & $0.0 \%$ & $1.5 \%$ & $0.5 \%$ & $0.0 \%$ & $0.7 \%$ & $0.0 \%$ & $0.0 \%$ & $1.2 \%$ \\
\hline \multirow{3}{*}{ Normal } & $\mathrm{N}$ & 6406 & 818 & 651 & 563 & 86 & 417 & 327 & 546 & 9814 \\
\hline & \% within LL & $65.3 \%$ & $8.3 \%$ & $6.6 \%$ & $5.7 \%$ & $0.9 \%$ & $4.2 \%$ & $3.3 \%$ & $5.6 \%$ & $100.0 \%$ \\
\hline & \% within Race & $98.3 \%$ & $100.0 \%$ & $98.0 \%$ & $99.5 \%$ & $100.0 \%$ & $99.3 \%$ & $100.0 \%$ & $100.0 \%$ & $98.7 \%$ \\
\hline \multirow{3}{*}{ Missing } & $\mathrm{N}$ & 4 & 0 & 3 & 0 & 0 & 0 & 0 & 0 & 7 \\
\hline & \% within LL & $57.1 \%$ & $0.0 \%$ & $42.9 \%$ & $0.0 \%$ & $0.0 \%$ & $0.0 \%$ & $0.0 \%$ & $0.0 \%$ & $100.0 \%$ \\
\hline & \% within Race & $0.1 \%$ & $0.0 \%$ & $0.5 \%$ & $0.0 \%$ & $0.0 \%$ & $0.0 \%$ & $0.0 \%$ & $0.0 \%$ & $.1 \%$ \\
\hline
\end{tabular}

RL: Right Lateral; LL: Left Lateral. 


\section{Discussion}

The prevalence of peg-shaped lateral incisors is considerably different for different races/ethnic groups, strengthening the view that genetic factors play an important role in its etiology. The prevalence of peg-shaped lateral incisors was found to be $7.5 \%$ and $1.6 \%$ in Asians and other races, respectively, in a study carried out in Minnesota [20]. In another study in Hawaii, the prevalence rates were significantly high in the Philippine descendants $(3.1 \%)$ as compared to whites $(1.7 \%)$, Chinese $(1.6 \%)$ and Japanese populations $(1.9 \%)$ [21]. These findings are in accordance with the current study as peg lateral prevalence rate was higher in Saudi population (1.6\%). A previous study showed that prevalence was significantly higher in Mongoloids $(3.1 \%)$ as compared to blacks $(1.5 \%)$ and whites (1.3\%). However, between the Mongoloids and North American people only, Mongoloids (2.0\%) had significantly higher prevalence as compared to whites (0.9\%) $[22]$.

Various studies have supported the view that environmental factors also play an important role in causing microdontia along with an underlying genetic mechanism. Studies have shown the prevalence of peglateral to be lower in North American white population as compared to those of Europe and Australia, strongly suggesting that the geographic location by itself can act as a decisive environmental factor [23]. Previous authors have shown that the prevalence of peg-laterals was higher in Europe as compared to North America with prevalence rates of $1.2 \%$ and $0.9 \%$, respectively. Similarly, the prevalence in Mongoloids (Asians) was higher than in North American population, with prevalence rates of $3.2 \%$ and $2.0 \%$, respectively. However, it was reported that the prevalence of peg-laterals in North American whites and blacks were similar at $1.3 \%$ and $1.5 \%$, respectively [22]. These findings are in accordance with the present study's findings, where a higher prevalence of peg laterals was found in Saudi region followed by Egypt. A study in the South Western region of Nigeria showed that the prevalence was $1 \%$ in the field sample as compared to $2.3 \%$ in their clinic-based sample. Such differences in the prevalence rates in different samples were attributed to the larger clinic-based sample compared to a smaller field sample [24]. According to a study by Farhana et al., the prevalence was relatively higher $(5.3 \%)$ in the Pakistani population compared to the other studies carried out in different geographic locations of the world [25]

Though these studies have shown a variation in the prevalence rates of peg-laterals in populations belonging to different geographic locations of the world, it was not significant indicating that such a small difference/variation could be due to some environmental differences prevailing at these locations.

Though the dental anomaly, the peg-shaped lateral is inherited as an autosomal dominant trait, various studies have yielded quite variable and controversial findings. According to previous findings, women are more likely to have peg-laterals as compared to men at a ratio of 1.35:1 [22]. However, contrary to this study, previous research showed that the frequency of peg laterals was more in males than in females [25]. The present study's findings also support that the prevalence of peg laterals is higher in males than females. Furthermore, there is no significant difference between the prevalence of peg laterals between males and females [8].

Since these studies were from different geographic locations, such contrasting results could again be attributed to some unsuspected, presumably environmental factors causing peg-laterals in such geographic locations. 


\section{Conclusion}

A higher prevalence of peg laterals was found in Saudi region followed by Egypt. Among all geographic locations, the prevalence of peg laterals was higher in males than females except for Pakistan and Philippines populations. Among Saudi population prevalence of peg laterals was found to be higher in case of right lateral incisor when compared to the left.

\section{Authors' Contributions}

\begin{tabular}{|c|c|c|}
\hline $\mathrm{SAH}$ & --- & Conceptualization, Methodology, Validation, Formal Analysis and Data Curation. \\
\hline AA & (iD) $0000-0003-0909-8713$ & $\begin{array}{l}\text { Methodology, Validation, Formal Analysis, Resources, Data Curation and Project } \\
\text { Administration. }\end{array}$ \\
\hline SMM & (iD) $0000-0001-9082-705 \mathrm{X}$ & $\begin{array}{l}\text { Resources, Writing - Original Draft, Writing - Review and Editing and } \\
\text { Supervision. }\end{array}$ \\
\hline KKG & (iD) $0000-0002-3178-9513$ & $\begin{array}{l}\text { Validation, Data Curation, Writing - Original Draft Preparation, Writing - } \\
\text { Review and Editing and Visualization. }\end{array}$ \\
\hline RKG & (iD) $0000-0003-3616-4042$ & $\begin{array}{l}\text { Validation, Writing - Original Draft Preparation, Writing - Review and Editing } \\
\text { and Visualization. }\end{array}$ \\
\hline $\mathrm{SF}$ & (D) $0000-0001-7365-293 \mathrm{X}$ & Methodology, Data Curation, Supervision and Funding Acquisition. \\
\hline SP & (iD) $0000-0003-0715-497 \mathrm{X}$ & $\begin{array}{l}\text { Validation, Writing - Original Draft Preparation, Writing - Review and Editing, } \\
\text { Visualization and Funding Acquisition. }\end{array}$ \\
\hline MKA & (iD) $0000-0001-7131-1752$ & $\begin{array}{l}\text { Conceptualization, Methodology, Data Curation, Writing - Original Draft } \\
\text { Preparation and Project Administration. }\end{array}$ \\
\hline
\end{tabular}

\section{Financial Support}

None.

\section{Conflict of Interest}

The authors declare no conflicts of interest.

\section{References}

[1] Grahnén H. Hypodontia in the permanent dentition. Odontol Revy 1956; 7:1-100.

[2] Nelson SJ. Wheeler's Dental Anatomy, Physiology and Occlusion. 10th ed. Philadelphia: Saunders/Elsevier; 2015.

[3] Ludwig FJ. The mandibular second premolars: morphologic variation and inheritance. J Dent Res 1957; 36(2):263-73. https://doi.org/10.1177/00220345570360021701

[4] Osborne RH, Horowitz SL, De George FV. Genetic variation in tooth dimensions: a twin study of the permanent anterior teeth. Am J Hum Genet 1958; 10(3):350-6.

[5] Lundström A. Tooth morphology as a basis for distinguishing monozygotic and dizygotic twins. Am J Hum Genet $1963 ; 15(1): 34-43$.

[6] Garn SM. Genetics of Dental Development. The Biology of Occlusal Development. Monograph 7, Craniofacial Growth Series. Ann Arbor: Center for Human Growth and Development, University of Michigan; 1977.

[7] Potter RH, Nance WE. A twin study of dental dimension. I. Discordance, asymmetry, and mirror imagery. Am J Phys Anthropol 1976; 44(3):391-5. https://doi.org/10.1002/ajpa.1330440303

[8] Alvesalo L, Portin P. The inheritance pattern of missing, peg-shaped, and strongly mesio-distally reduced upper lateral incisors. Acta Odontol Scand 1969; 27(6):563-75. https://doi.org/10.3109/00016356909026309

[9] Witkop Jr CJ. Agenesis of succedaneous teeth: an expression of the homozygous state of the gene for the pegged or missing maxillary lateral incisor trait. Am J Med Genet 1987; 26(2):431-6. https://doi.org/10.1002/ajmg.1320260222

[10] Pinho T, Maciel P, Pollmann C. Developmental disturbances associated with agenesis of the permanent maxillary lateral incisor. Br Dent J 2009; 207(12):E25. https://doi.org/10.1038/sj.bdj.2009.961

[11] Brook AH. A unifying aetiological explanation for anomalies of human tooth number and size. Arch Oral Biol 1984; 29(5):373-8. https://doi.org/10.1016/0003-9969(84)90163-8 
[12] Vastardis H. The genetics of human tooth agenesis: new discoveries for understanding dental anomalies. Am J Orthod Dentofacial Orthop 2000; 117(6):650-6.

[13] Salem G. Prevalence of selected dental anomalies in Saudi children from Gizan region. Community Dent Oral Epidemiol 1989; 17(3):162-3. https://doi.org/10.1111/j.1600-0528.1989.tb00014.x

[14] Amin F, Asif J, Akber S. Prevalence of peg laterals and small size lateral incisors in orthodontic patients - a study. Pak Oral Dental J 2011; 31(1):88-91.

[15] Gupta SK, Saxena P, Jain S, Jain D. Prevalence and distribution of selected developmental dental anomalies in an Indian population. J Oral Sci 2011; 53(2):231-8. https://doi.org/10.2334/josnusd.53.231

[16] Albashaireh ZSM, Khader YS. The prevalence and pattern of hypodontia of the permanent teeth and crown size and shape deformity affecting upper lateral incisors in a sample of Jordanian dental patients. Community Dent Health 2006; 23(4):239-43.

[17] Thilander B, Myrberg N. The prevalence of malocclusion in Swedish schoolchildren. Scand J Dent Res 1973; 81(1):12-21. https://doi.org/10.1111/j.1600-0722.1973.tbo1489.x

[18] Thongudomporn U, Freer TJ. Prevalence of dental anomalies in orthodontic patients. Aust Dent J 1998; 43(6):395-8.

[19] von Elm E, Altman DG, Egger M, Pocock SJ, Gøtzsche PC, Vandenbroucke JP, et al. The strengthening the reporting of observational studies in epidemiology (STROBE) Statement: Guidelines for reporting observational studies. Int J Surg 2014; 12(12):1495-9. https://doi.org/10.1016/j.ijsu.2014.07.013

[20] Stecker SS, Beiraghi S, Hodges JS, Peterson VS, Myers SL. Prevalence of dental anomalies in a Southeast Asian population in the Minneapolis/Saint Paul metropolitan area. Northwest Dent 2006; 86(5):25-8.

[21] Chung CS, Niswander JD, Runck DW, Bilben SE, Kau MC. Genetic and epidemiologic studies of oral characteristics in Hawaii's school children: dental anomalies. Am J Phys Anthropol 1972; 36(3):427-33. https://doi.org/10.1002/ajpa.1330360314

[22] Hua F, He H, Ngan P, Bouzid W. Prevalence of peg-shaped maxillary permanent lateral incisors: a meta-analysis. Am J Orthod Dentofacial Orthop 2013; 144(1):97-109. https://doi.org/10.1016/j.ajodo.2013.02.025

[23] Higgins JPT, Thompson SG, Deeks JJ, Altman DG. Measuring inconsistency in meta-analyses. BMJ 2003; 327(7414):557-60. https://doi.org/10.1136/bmj.327.7414.557

[24] Ucheonyne I TA. Prevalence of peg-shaped laterals in Southwestern Nigeria: a comparison of field and clinic findings. Internet J Dent Sci 2009; 8(2):1-5.

[25] Afzal F, Rasool G, Bashir S, Afzal S, Gul H. Prevalence of congenitally missing maxillary lateral incisor and peg laterals in a local orthodontic population. JKCD 2015; 5(2):29-33. 